OPEN

SUBJECT AREAS:

TISSUE CULTURE

LAB-ON-A-CHIP

Received

29 January 2014

Accepted

7 April 2014

Published

24 April 2014

Correspondence and requests for materials should be addressed to M.K. (kamihira@chemeng.kyushu-u.ac.jp)

* These authors contributed equally to this work.

$\uparrow$ Current address: Laboratory for

Comprehensive

Bioimaging, Riken

Qbic, 6-2-3 Furuedai,

Suita, Osaka 565-

0874, Japan.

* Current address:

Department of

Biotechnology,

Graduate School of

Engineering, Osaka

University, 2-1

Yamadaoka, Suita,

Osaka 565-0871,

Japan.

\section{Induction of functional tissue-engineered skeletal muscle constructs by defined electrical stimulation}

\author{
Akira lto $*$, Yasunori Yamamoto ${ }^{2 *}$, Masanori Sato', Kazushi lkeda², Masahiro Yamamoto', \\ Hideaki Fujita ${ }^{3} \dagger$, Eiji Nagamori ${ }^{3} \leftarrow$, Yoshinori Kawabe ${ }^{1} \&$ Masamichi Kamihira ${ }^{1,2}$
} 'Department of Chemical Engineering, Faculty of Engineering, Kyushu University, 744 Motooka, Nishi-ku, Fukuoka 819-0395,
Japan, ${ }^{2}$ Graduate School of Systems Life Sciences, Kyushu University, 744 Motooka, Nishi-ku, Fukuoka 819-0395, Japan, ${ }^{3}$ Toyota
Central R\&D Laboratories Inc., 41-1 Yokomichi, Nagakute, Aichi 480-1 192, Japan.

Electrical impulses are necessary for proper in vivo skeletal muscle development. To fabricate functional skeletal muscle tissues in vitro, recapitulation of the in vivo niche, including physical stimuli, is crucial. Here, we report a technique to engineer skeletal muscle tissues in vitro by electrical pulse stimulation (EPS). Electrically excitable tissue-engineered skeletal muscle constructs were stimulated with continuous electrical pulses of $0.3 \mathrm{~V} / \mathrm{mm}$ amplitude, $4 \mathrm{~ms}$ width, and $1 \mathrm{~Hz}$ frequency, resulting in a 4.5 -fold increase in force at day 14. In myogenic differentiation culture, the percentage of peak twitch force $(\% \mathrm{Pt})$ was determined as the load on the tissue constructs during the artificial exercise induced by continuous EPS. We optimized the stimulation protocol, wherein the tissues were first subjected to $24.5 \% \mathrm{Pt}$, which was increased to $50-60 \% \mathrm{Pt}$ as the tissues developed. This technique may be a useful approach to fabricate tissue-engineered functional skeletal muscle constructs.

keletal muscle tissue engineering holds great promise for regenerative medicine $e^{1,2}$. The in vivo niche of skeletal muscle plays a crucial role in myogenic differentiation ${ }^{3,4}$. Skeletal muscles are composed of dense and oriented myocytes (muscle fibers) that are bundled into fascicles, which are further bundled together into muscles. Muscle fibers are sheathed by a perimysium that contains nerves and blood vessels. We believe that in vitro fabrication of fascicles, as a functional unit of skeletal muscle, is a promising approach for skeletal muscle tissue engineering because of the difficulty in forming perfusable blood vessels within in vitro tissue constructs to supply oxygen and nutrients ${ }^{5}$. The use of collagen as a three-dimensional matrix support is consistent with its role in native muscle, and the tension generated within collagen-based tissues is crucial for muscle development and formation of oriented muscular tissues $s^{6,7}$. We previously developed a "magnetic force-based tissue engineering (Mag-TE)"8-10 technique, in which myoblast cells labeled with functionalized magnetic nanoparticles were concentrated to form highly cell-dense muscular tissues by applying a magnetic force ${ }^{11}$. To date, however, fully functional skeletal muscle tissue constructs have not been fabricated in vitro using this method.

Electrical impulse stimulation from the central nervous system via the motor neurons is the most important cue for skeletal muscle development and maturation ${ }^{12}$. We hypothesized that electrical pulse stimulation (EPS) mimics the electrical cues in the in vivo niche, allowing the creation of functional skeletal muscle tissues in vitro. It is well known that physiological electrical impulses can be modeled in vitro by tuning EPS parameters such as voltage amplitude, pulse width, and frequency. However, methodology for controlling these stimulation parameters to develop in vitro functional skeletal muscle tissues remains to be established. Inappropriate EPS parameters can result in electrochemical damage to the tissues. Too high voltages typically cause electroporation ${ }^{13}$, which plays a greater role in electrochemical damage than pulse width. Electrical damage has been observed above $2.5 \mathrm{~V} / \mathrm{mm}$ and at frequencies over $3 \mathrm{~Hz}^{14}$. Additionally, a previous study reported that the force production ability of myotubes decreased rapidly after termination of continuous EPS with changes in atrophy-related gene expression $^{15}$, indicating the importance of continuous EPS without rest. Therefore, in the present study, we investigated continuous EPS parameter ranges of $0.1-0.5 \mathrm{~V} / \mathrm{mm}$ pulse amplitudes, 2-10 ms pulse widths, and $0.5-2 \mathrm{~Hz}$ frequencies.

Force production is the most important characteristics of muscle, which reflects its functionality and developmental maturity. The force production capability of muscle tissues is typically evaluated using physiological parameters, such as peak twitch force $(\mathrm{Pt})$ and excitability. Excitability is measured by adjusting the stimulus 
intensity to produce a force of $50 \% \mathrm{Pt}$, and the resultant voltage required to elicit a $50 \% \mathrm{Pt}$ is defined as rheobase ${ }^{16}$. Notably, this active tension measurement is a nondestructive test, unlike biochemical and histological analyses. In the past years, reports of the contractility data presented in terms of force have increased in number ${ }^{11,17-20}$. We hypothesized that fine-tuning EPS stimulation during in vitro myogenic differentiation culture would allow development of skeletal muscle tissue constructs with higher force production. Here, we introduce \%Pt as an EPS parameter representing "load" on the tissue constructs during artificial exercise induced by continuous EPS. The aim of this study was to determine the optimum EPS protocol to create in vitro skeletal muscle tissues by monitoring force production.

\section{Results}

Formation of electrically excitable tissue-engineered skeletal muscles on day 4. In vitro tissue-engineered skeletal muscles composed of mouse myoblast $\mathrm{C} 2 \mathrm{C} 12$ cells $^{21}$ were prepared using the Mag-TE technique (Supplementary Fig. S1). We used mouse myoblast $\mathrm{C} 2 \mathrm{C} 12$ cells to exclude non-myogenic cell types from the tissue constructs. C2C12 cells were magnetically labeled with magnetite cationic liposomes, which enabled us to concentrate the cells by magnetic force to form more densely packed, uniformly aligned, and thin $(\sim 350 \mu \mathrm{m})$ fasciclelike structures surrounded by collagenous membranes compared with muscular tissues constructed by conventional gel-based techniques (Supplementary Fig. S2a). Notably, although the force production profiles of both tissue constructs were similar (Supplementary Fig. S2b), the specific force produced by the tissue constructs prepared using the Mag-TE technique was higher than that of the gel-based tissue constructs (Supplementary Fig. S2c) owing to differences in their cross-sectional areas. Because the in vitro skeletal muscle tissues began to generate contractile force in response to EPS after 4 days of myogenic differentiation culture (day 4) (Fig. 1a), we measured the contractile properties on day 4 of EPS culture. Lowfrequency electrical stimulation at $0.5,1$, and $2 \mathrm{~Hz}$ induced individual twitch contractions (Fig. 1b), while the additional activation of contractile elements, called tetanus, was observed after repeated stimulation with high-frequency electrical pulses at $50 \mathrm{~Hz}$ (Fig. 1a). The twitch force at various voltages (Fig. 1c) and pulse widths (Fig. 1d) was measured, and we determined $\% \mathrm{Pt}$ at different voltages $(0.1,0.3$, and $0.5 \mathrm{~V} / \mathrm{mm}$ ) and pulse widths $(2,4$, and $10 \mathrm{~ms}$ ) (Supplementary Fig. S3 and Fig. 1e), as the load on tissue constructs induced by EPS.

The effects of EPS on in vitro skeletal muscle tissues from days 4 to 7. In vitro skeletal muscle tissues were cultured for 3 days after day 4 with continuous EPS at the various voltages and pulse widths shown in Figure 1e, and peak twitch force was measured on day 7 (Fig. 2a). When the tissue constructs were cultured with continuous EPS at $1 \mathrm{~Hz}, 0.3 \mathrm{~V} / \mathrm{mm}$, and $4 \mathrm{~ms}$, the tissue constructs generated the highest peak twitch force of $41.7 \pm 3.5 \mu \mathrm{N}$ (Fig. 2a and Supplementary Fig. S4). Next, we rearranged the data in Figure 2a on the basis of $\% \mathrm{Pt}$, and evaluated the effect of $\% \mathrm{Pt}$ on force production. The force production peaked at $24.5 \% \mathrm{Pt}$ and was drastically reduced in the tissue constructs cultured with EPS at $97.0 \% \mathrm{Pt}$ (Fig. 2b). Compared with $24.5 \% \mathrm{Pt}$ EPS at $1 \mathrm{~Hz}$, the force production was low when the tissue constructs were cultured with 0.5 or $2 \mathrm{~Hz}$ (Fig. 2c). Moreover, compared with non-EPS tissue constructs, the amount of protein within tissue constructs cultured with $1 \mathrm{~Hz}$ EPS $(0.3 \mathrm{~V} / \mathrm{mm}, 4 \mathrm{~ms})$ was significantly $(P<0.05)$ higher (Fig. $2 \mathrm{~d})$, whereas no difference $(P=0.28)$ was observed in the number of nuclei (Fig. 2e). High EPS at 97.0\%Pt $(0.5 \mathrm{~V} / \mathrm{mm}, 10 \mathrm{~ms})$ caused a decrease in force (Fig. 2c), protein content (Fig. 2d), and the number of nuclei (Fig. 2e), indicating electrochemical damage. Conversely, for $2 \mathrm{~Hz}$ EPS, the levels of force production, protein content, and nuclei number were similar to those of non-EPS tissue constructs (Figs $2 \mathrm{c}-\mathrm{e}$ ), indicating an ineffective EPS level for tissue constructs from days 4 to 7 .
The effects of EPS on in vitro skeletal muscle tissues from days 7 to 10. We next determined whether EPS signals could be tuned during the myogenic differentiation culture period. We examined the force production of the tissue constructs cultured with $1 \mathrm{~Hz}$ EPS at $24.5 \% \mathrm{Pt}$ from days 4 to 7 , and assessed \% Pt for different EPS conditions on day 7 (Fig. 3a). Because the optimum EPS condition was found to be $24.5 \% \mathrm{Pt}$ for days 4 to 7 , EPS was set at $24.5 \% \mathrm{Pt}$ on day 4 and then changed to $\sim 20, \sim 50$, or $\sim 80 \% \mathrm{Pt}$ on day 7 (Supplementary Fig. S5) and applied for 3 days (Fig. 3b). On day 10 , the tissue constructs stimulated with EPS at $\sim 50 \% \mathrm{Pt}$ demonstrated the highest force production (Fig. 3c). The changes in force production were dependent on \% $\mathrm{Pt}$, regardless of electrical signal parameters such as pulse voltage and width (Fig. 3c).

The effects of EPS on in vitro skeletal muscle tissues at day 14. The optimum EPS protocol that started with $\sim 20 \% \mathrm{Pt}$ at day 4 and then changed to $\sim 50 \% \mathrm{Pt}$ at day 7 was determined when the tissue constructs were cultured with continuous $1 \mathrm{~Hz}$ EPS at a pulse amplitude of $0.3 \mathrm{~V} / \mathrm{mm}$ and a width of $4 \mathrm{~ms}$ (Fig. 3). After establishing the EPS parameters, we next examined the effects of a 10-day continuous EPS exposure on the functions of in vitro tissueengineered muscle tissues. The force production increased linearly with culture time, resulting in a 4.5 -fold increase in force at day 14 compared with non-EPS tissue constructs (Fig. 4a). During the continuous EPS culture from days 4 to 14, EPS production was $24.5 \pm 2.0 \% \mathrm{Pt}$ on day 4 , increased to $54.1 \pm 7.6 \% \mathrm{Pt}$ on day 7 , and remained steady at $50 \sim 60 \% \mathrm{Pt}$ on days 7 to 14 (Fig. $4 \mathrm{~b}$ ), indicating that low-intensity EPS was effective during the early stage of myogenic differentiation on day 4. For EPS tissue constructs, a rapid decrease in rheobase from days 4 to 7 indicated a marked increase in excitability during the early stage of myogenic differentiation (Fig. 4c). Western blotting of EPS tissue construct extracts revealed a substantial increase in the expression of myosin heavy chain (MHC) and tropomyosin from days 4 to 7 (Fig. 4d). These results suggest that EPS is an effective cue for myogenic differentiation. Similarly, prominent striation patterns containing sarcomeric $\alpha$-actinin were observed in EPS tissue constructs on day 14 (Fig. 4e). Compared with non-EPS tissue constructs (Supplementary Video 1), EPS tissue constructs showed vigorous contraction in response to electric stimulation (Supplementary Video 2). When tissue constructs were cultured with the optimized EPS protocol determined here, the maximum twitch and tetanus force at day 14 were $116.7 \pm 14.7 \mu \mathrm{N}$ and $182.4 \pm 33.0 \mu \mathrm{N}$ (Fig. $4 \mathrm{f}$ ), respectively.

\section{Discussion}

EPS is known to enhance the maturation of the muscle cells, including myoblast cells ${ }^{14,22}$ and cardiomyocytes ${ }^{23,24}$. Radisic et al. reported that continuous EPS $(0.5 \mathrm{~V} / \mathrm{mm}, 2 \mathrm{~ms}, 1 \mathrm{~Hz})$ that are characteristic for native myocardium resulted in the progressive development of conductive and contractile properties in cardiac constructs over 8 days of culture ${ }^{25}$. In the present study, we determined an optimized protocol for EPS, in which the skeletal muscle constructs were cultured at pulse amplitude of $0.3 \mathrm{~V} / \mathrm{mm}$, width of $4 \mathrm{~ms}$, and frequency of $1 \mathrm{~Hz}$ for 10 days (Fig. 4). Unlike in vivo neural stimulation in which action potential is propagated along the surface of the muscle cell membrane, EPS with pulse width longer than $0.4 \mathrm{~ms}$ causes direct calcium release from the sarcoplasmic reticulum ${ }^{26}$. In the present study, the optimized protocol for EPS was obtained by using a longer pulse width (4 ms, Fig. 4), which may be different from in vivo neural stimulation. In the future, the in vitro skeletal muscle tissues will have to be adapted and refined, for example, by co-culturing with motor neurons to improve the comparability of the tissue-engineered constructs with in vivo muscle. Recently, Khodabukus and Baar reported that continuous 24-h EPS to 14-day culture tissue constructs at pulse amplitude of $1 \mathrm{~V} / \mathrm{mm}$ and width of $4 \mathrm{~ms}$, which corresponded to $100 \% \mathrm{Pt}$, resulted in a 2 -fold increase in force ${ }^{27}$, 
(a)

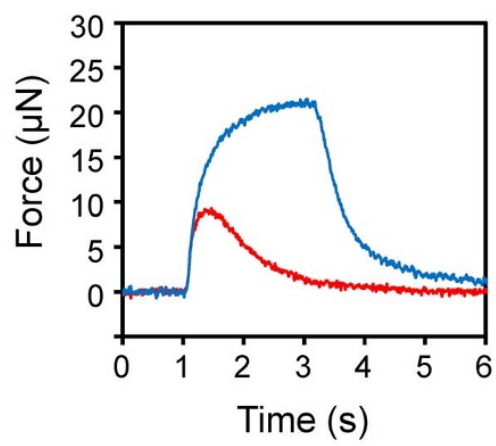

(c)

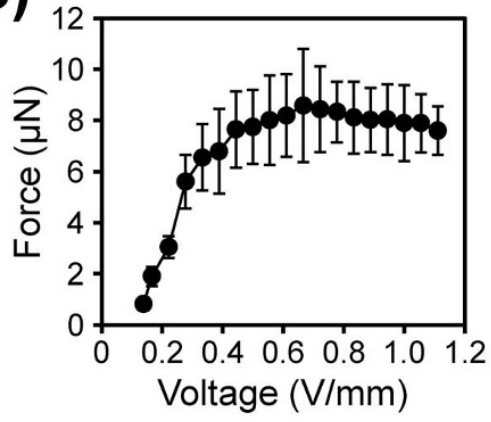

(b)
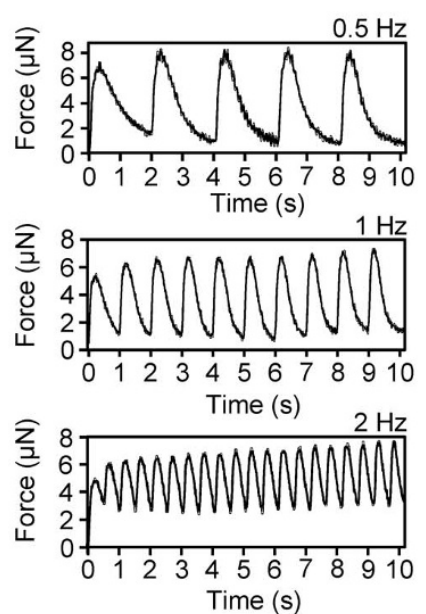

(d)

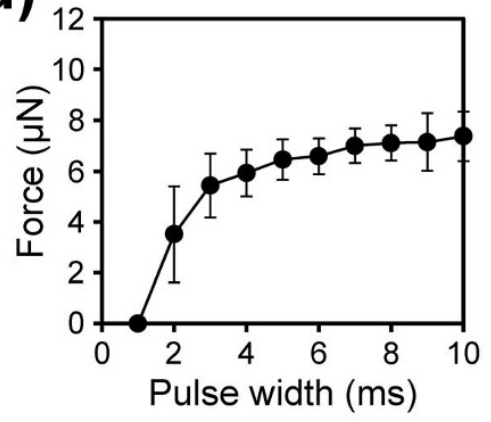

(e)

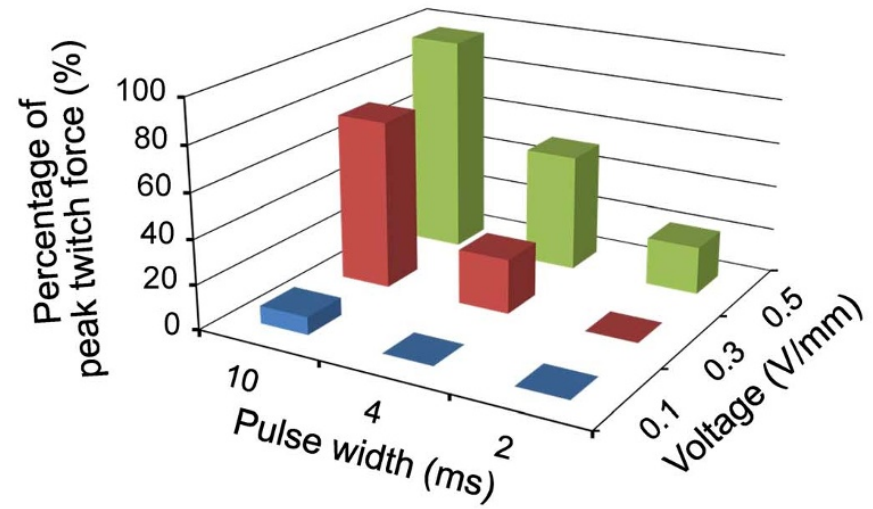

Figure 1 Formation of electrically excitable tissue-engineered skeletal muscles at day 4. (a) A representative peak twitch force using a single electric pulse (red line; voltage: $0.83 \mathrm{~V} / \mathrm{mm}$, width: $10 \mathrm{~ms}$ ) and fusion of tetanus (blue line; voltage: $0.83 \mathrm{~V} / \mathrm{mm}$, width: $10 \mathrm{~ms}$; frequency: $50 \mathrm{~Hz}$, duration: $2 \mathrm{~s}$ ) generated by the in vitro skeletal muscle tissue constructs. (b) The force-frequency diagram for the tissue construct. Electric stimulations (voltage: $0.83 \mathrm{~V} / \mathrm{mm}$, width: $10 \mathrm{~ms}$ ) with frequencies of $0.5,1$, or $2 \mathrm{~Hz}$ were applied to the tissue construct and twitch forces were monitored. (c) The effect of pulse voltage on force production. Using a $10-\mathrm{ms}$ pulse width, the voltage was incrementally increased (mean \pm SD of three constructs). (d) The effect of pulse width on force production. Using a $0.5 \mathrm{~V} / \mathrm{mm}$ voltage, the pulse width was incrementally increased (mean \pm SD of three constructs). (e) The percentage of peak twitch force $(\% \mathrm{Pt})$ generated by the in vitro skeletal muscle tissues. To determine $100 \% \mathrm{Pt}$, peak twitch force was measured by using a single electric pulse at $0.83 \mathrm{~V} / \mathrm{mm}$ and $10 \mathrm{~ms}$, and \% Pt at each electric stimulation was determined by measuring the peak twitch force. \%Pt increased proportionately within the range of electric pulses tested (voltage: $0.1-0.5 \mathrm{~V} / \mathrm{mm}$; width: $2-10 \mathrm{~ms}$ ).

suggesting that high \%Pt may be required to increase force production when using short-duration, acute EPS. However, we demonstrated here that low \%Pt was effective for long-duration, chronic EPS, as we achieved a 4.5 -fold increase in force by low \%Pt EPS culture (Fig. 4a) without a reduction in force production due to electrochemical damage.

In the present study, we showed that EPS at the same $\% \mathrm{Pt}$ increased force production to similar levels, independent of changes in pulse amplitude and/or width (Fig. 3c), indicating that the "load" on the tissue constructs played a crucial role indeed in the increased force production. For in vivo muscle, strength training is dependent on the load across the muscle during exercise ${ }^{28}$. It is difficult to directly compare the effects of in vivo exercise and the effects of EPS culture on in vitro tissue-engineered skeletal muscle constructs. However, our tissue culture model employing EPS may be useful not only for analyzing myogenic differentiation in the field of skeletal muscle tissue engineering, but also to study EPS treatment for skeletal muscle atrophy caused by mechanical unloading after denervation, aging, or spaceflight because there are many similarities between embryonic muscle development and adult muscle regeneration ${ }^{29}$. 
(a)

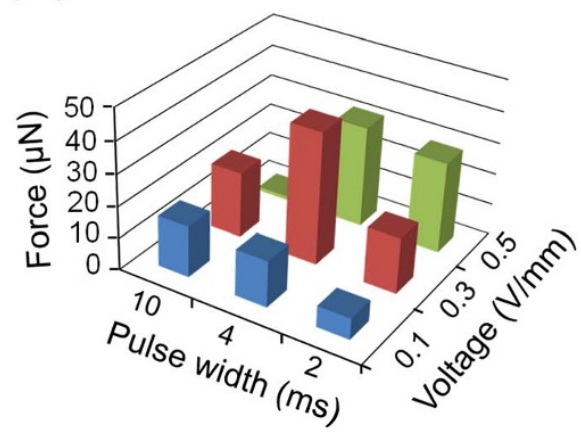

(c)

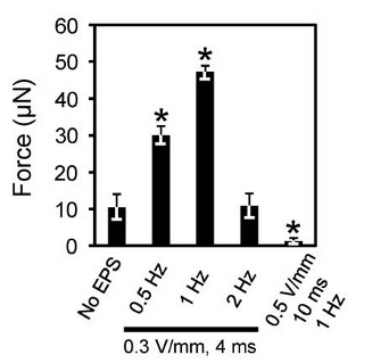

(d)

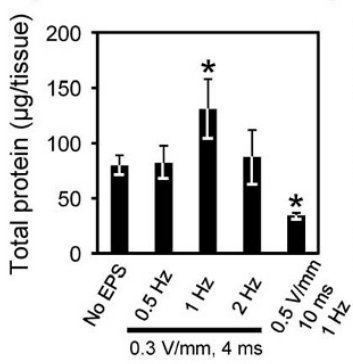

(b)

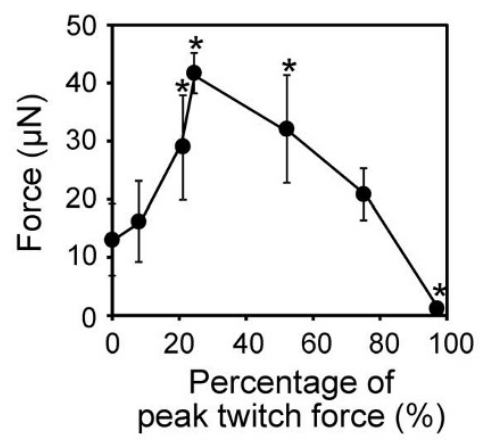

(e)

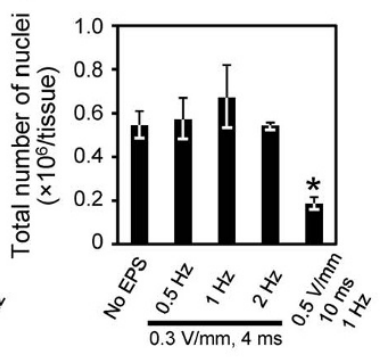

Figure $2 \mid$ The effects of EPS on in vitro skeletal muscle tissues from days 4 to 7. (a) Peak twitch force generation of EPS-treated tissue constructs on day 7. The tissue constructs were cultured with continuous $1 \mathrm{~Hz}$ EPS at various voltages $(0.1,0.3$, or $0.5 \mathrm{~V} / \mathrm{mm})$ and pulse widths (2, 4 , or $10 \mathrm{~ms})$ for 3 days starting on day 4 , and peak twitch force was measured on day 7 using a single electric pulse (voltage: $0.83 \mathrm{~V} / \mathrm{mm}$, width: $10 \mathrm{~ms}$ ). (b) Relationship between $\% \mathrm{Pt}$ at day 4 and force production at day 7. Data are shown as mean \pm SD of three constructs. ${ }^{*} P<0.05 \mathrm{vs}$. $0 \% \mathrm{Pt}$. (c-e) The effects of EPS frequency during myogenic differentiation on the force production (c), the amount of protein (d), and the number of nuclei (e) in the tissue constructs at day 7 . The data are expressed as mean \pm SD of three constructs. ${ }^{*} P<0.05$ vs. non-EPS constructs.

Because in vitro tissue-engineered skeletal muscles are in an early developmental state, the increased force production by EPS is most likely caused by organization of the sarcomeres ${ }^{22}$ and expression of $\mathrm{MHC}^{30}$. Force production capability, which is the most important characteristic of skeletal muscles, reflects both the expression level of MHC (Fig. 4d) and sarcomere structure (Fig. 4e), making it an ideal indicator of the extent of myogenic differentiation and maturation. Additionally, because the active tension measurement is a nondestructive test, EPS parameters can be tuned during myogenic differentiation culture as in vitro skeletal muscle tissues develop. In the present study, we started EPS culture on day 4 and changed EPS parameters every 3 days (on day 7 and day 10) (Figs. 2 and 3). In the future, real-time control of EPS by monitoring force production as \% Pt may be a useful approach to fabricate tissue-engineered functional skeletal muscle constructs in vitro.

In conclusion, we proposed the novel concept of using \% Pt as the load on tissue constructs, which may be a useful approach to fabricate tissue-engineered functional skeletal muscle constructs. In the present study, we determined the optimum EPS to create in vitro skeletal muscle tissues by measuring the force production during myogenic differentiation culture. While the concepts regarding the $\% \mathrm{Pt}$ may be quite useful, the mechanism remains to be elucidated and the optimum EPS may vary due to the materials and methods including cells, tissue fabrication technique and culture conditions. Currently, effects of the optimum EPS culture on primary myoblasts are being investigated.

\section{Methods}

Fabrication of in vitro skeletal muscle tissues. As previously described ${ }^{31}$, magnetite cationic liposomes (MCLs) were prepared from colloidal magnetite and a lipid mixture consisting of $N$-( $\alpha$-trimethylammonioacetyl)-didodecyl-D-glutamate chloride, dilauroylphosphatidylcholine, and dioleoylphosphatidyl-ethanolamine, in a molar ratio of $1: 2: 2$. The magnetite nanoparticles $\left(\mathrm{Fe}_{3} \mathrm{O}_{4}\right.$; average particle size: $10 \mathrm{~nm}$ ) were obtained from Toda Kogyo (Hiroshima, Japan). The magnetic characteristics at $796 \mathrm{kA} / \mathrm{m}$ (room temperature) were $2.0 \mathrm{kA} / \mathrm{m}$ coercivity, 63.9 $\mathrm{Am}^{2} / \mathrm{kg}$ saturation flux density, and $2.6 \mathrm{Am}^{2} / \mathrm{kg}$ remanent flux density.

To magnetically label the $\mathrm{C} 2 \mathrm{C} 12$ cells, $7 \times 10^{5}$ cells were seeded in 100 -mm tissue culture dishes containing $10 \mathrm{~mL}$ of culture medium in the presence of MCLs (net magnetite concentration: $100 \mathrm{pg} / \mathrm{cell}$ ), and incubated for $8 \mathrm{~h}$ to allow for MCL uptake. The in vitro skeletal muscle tissues were prepared as previously described ${ }^{32}$. The incubation scheme is illustrated in Supplementary Figure S1. Briefly, a polycarbonate cylinder (diameter: $12 \mathrm{~mm}$ ) was fixed with an adhesive to the center of a well of a 24-well ultralow-attachment culture plate (Corning, New York, NY, USA). MCL-labeled C2C12 cells $\left(1 \times 10^{6}\right.$ cells) were seeded into the ring-shaped gap, and a cylindrical neodymium magnet (diameter: $30 \mathrm{~mm}$; height: $15 \mathrm{~mm}$; magnetic induction: $0.4 \mathrm{~T}$ ) was placed under the well. Next, the cells were cultured in growth medium consisting of Dulbecco's-modified Eagle's medium (DMEM), supplemented with $10 \%$ fetal bovine serum, $100 \mathrm{U} / \mathrm{mL}$ penicillin $\mathrm{G}$ potassium, and $0.1 \mathrm{mg} / \mathrm{mL}$ streptomycin sulfate, for $12 \mathrm{~h}$ to allow for the formation of a ring-shaped cellular construct. After $12 \mathrm{~h}$ culture, $0.1 \mathrm{~mL}$ of an extracellular matrix solution consisting of $0.04 \mathrm{~mL}$ of type I collagen $(1.1 \mathrm{mg} / \mathrm{mL}$; Nitta Gelatin, Osaka, Japan), $0.01 \mathrm{~mL}$ of the growth medium, and $0.05 \mathrm{~mL}$ of Matrigel $(4.4 \mathrm{mg} / \mathrm{mL}$; BD Biosciences, Franklin Lakes, NJ, USA) were poured into the well and then quickly replaced with culture medium to coat the tissue construct with extracellular matrix. After $4 \mathrm{~h}$, the ringshaped tissue construct was removed from the polycarbonate cylinder and hooked around two stainless-steel minutien pins ( $0.3 \mathrm{~mm}$ diameter; Shiga, Tokyo, Japan) and fixed $6 \mathrm{~mm}$ apart from one another on a silicone rubber sheet in a 35- $\mathrm{mm}$ culture dish. To induce myogenic differentiation, the tissue constructs were cultured in differentiation medium consisting of DMEM supplemented with $0.4 \%$ Ultroser $\mathrm{G}^{33}$ (Pall, East Hills, NY, USA), $100 \mathrm{U} / \mathrm{mL}$ penicillin G potassium, and $0.1 \mathrm{mg} / \mathrm{mL}$ streptomycin sulfate.

As a control, tissue constructs were prepared without using MCLs and magnetic force by a gel-based method. C2C12 cells $\left(1 \times 10^{6}\right.$ cells $)$ suspended in the extracellular matrix solution $(0.3 \mathrm{~mL})$ were added into the ring-shaped gap, and cultured in the growth medium. After $12 \mathrm{~h}$, the cellular ring was removed from the polycarbonate cylinder and hooked around the stainless-steel minutien pins (Shiga) in a $35-\mathrm{mm}$ culture dish. To induce myogenic differentiation, the cellular rings were cultured for 4 days in the differentiation medium.

Tension measurement. Active tension generated by muscular tissues was measured as described previously ${ }^{11}$. Briefly, carbon electrodes were placed $18 \mathrm{~mm}$ apart at 

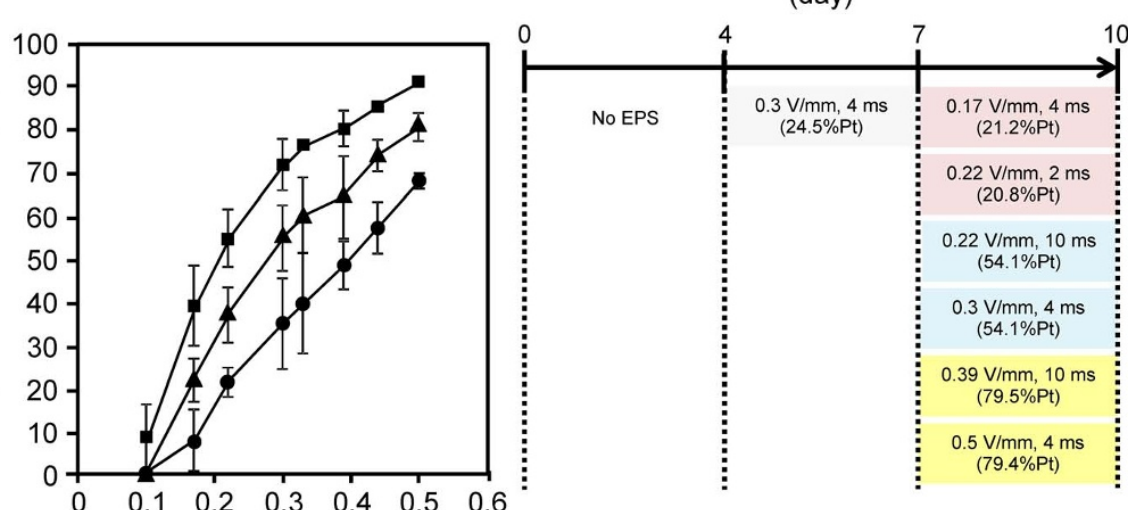

Voltage $(\mathrm{V} / \mathrm{mm})$

(c)

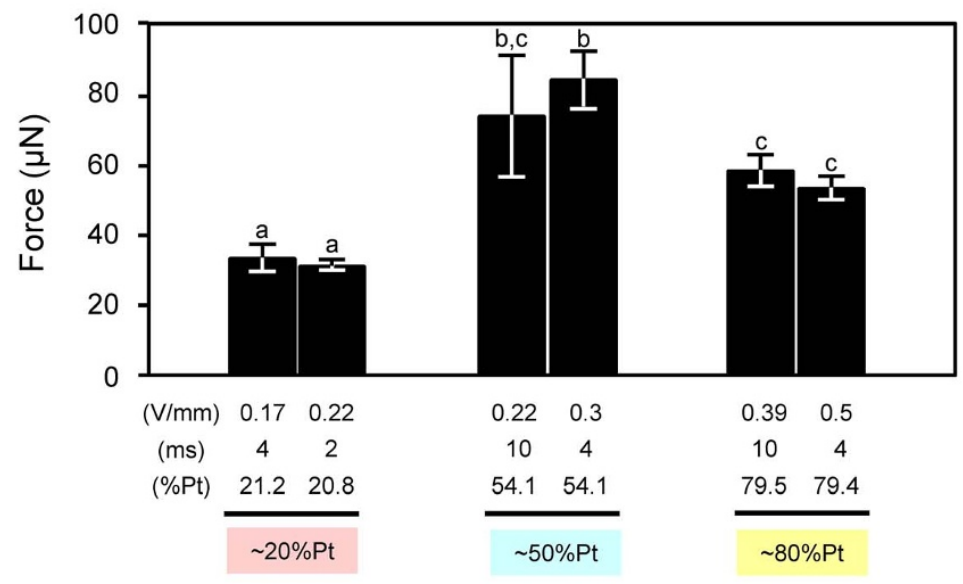

Figure $3 \mid$ The effects of EPS on in vitro skeletal muscle tissues from days 7 to 10. (a) \%Pt of the EPS-treated tissue constructs on day 7 . The tissue constructs were cultured with $1 \mathrm{~Hz}$ EPS at $0.3 \mathrm{~V} / \mathrm{mm}$ and $4 \mathrm{~ms}$ from days 4 to 7 , and \%Pt was evaluated on day 7 . Circles: $2 \mathrm{~ms}$; triangles: $4 \mathrm{~ms}$; squares: $10 \mathrm{~ms}$. Data are shown as mean \pm SD of three constructs. (b) EPS protocol during myogenic differentiation culture. (c) EPS culture was started at $24.5 \% \mathrm{Pt}$ on day 4 , changed to $\sim 20 \% \mathrm{Pt}(20.8 \pm 3.4 \% \mathrm{Pt}$ or $21.2 \pm 5.0 \% \mathrm{Pt}), \sim 50 \% \mathrm{Pt}(54.1 \pm 6.7 \% \mathrm{Pt}$ or $54.1 \pm 7.6 \% \mathrm{Pt})$, or $\sim 80 \% \mathrm{Pt}(79.4 \pm 3.3 \% \mathrm{Pt}$ or $79.5 \pm 4.2 \% \mathrm{Pt})$ on day 7 , and then force production was measured on day 10. Data are shown as mean \pm SD of three constructs. Columns that were statistically indistinguishable $(P>0.05)$ are marked with the same letter.

opposite sides of a tissue culture plate. An in vitro skeletal muscle tissue was hooked around two stainless-steel minutien pins: one pin was attached to a force transducer (AE-801; SensorOne, Sausalito, CA, USA) and the other was fixed to the silicon rubber sheet placed on the bottom of the culture plate well. The generation of electric pulses was controlled by a customized LabView interface (National Instruments, Austin, TX, USA). When measuring peak twitch force, the tissue construct was stimulated with an electric pulse of $0.83 \mathrm{~V} / \mathrm{mm}$ and width of $10 \mathrm{~ms}$. When measuring tetanic contraction, the tissue construct was stimulated with electric pulses of $0.83 \mathrm{~V} / \mathrm{mm}$ voltage, $10 \mathrm{~ms}$ width, $50 \mathrm{~Hz}$ frequency, and $2 \mathrm{~s}$ duration. The frequency response of the tissue constructs was evaluated by applying a pulse amplitude of $0.83 \mathrm{~V} / \mathrm{mm}$, width of $10 \mathrm{~ms}$, and frequencies of $0.5,1$, or $2 \mathrm{~Hz}$. The excitability of tissue constructs was measured by first applying a 10 -ms single stimulus pulse while adjusting the stimulus intensity to achieve a force of $50 \% \mathrm{Pt}$. The resulting voltage required to elicit a $50 \% \mathrm{Pt}$ was defined as rheobase.

Electric pulse stimulation during tissue culture. Four days after the induction of differentiation, the in vitro skeletal muscle tissues in a 4-lane or 6-well plate were placed in a chamber (C-Dish; IonOptix, Milton, MA, USA) to apply EPS. The tissue constructs were placed between two carbon electrodes placed $74.7 \mathrm{~mm}$ (4-lane plate) or $20.3 \mathrm{~mm}$ (6-well plate) apart. Bi-directional electric pulses were generated by a function generator (NF Corporation, Kanagawa, Japan), alternator (Matsusada Precision, Shiga, Japan), and amplifier (Apex Microtechnology, Tucson, AZ, USA). The differentiation medium was replaced daily.

Histology. Tissues were washed three times with phosphate-buffered saline (PBS), fixed in $4 \%$ paraformaldehyde (PFA) in PBS, and embedded in paraffin. Thin sections $(4 \mu \mathrm{m})$ were prepared, stained with hematoxylin and eosin, and then observed under a BZ-9000 microscope (Keyence, Tokyo, Japan). Prior to immunostaining, tissues were washed with PBS and fixed in 4\% PFA for $15 \mathrm{~min}$. They were then permeabilized in PBS containing $0.2 \%$ Triton X-100 for 15 min, washed three times with PBS, and blocked in PBS containing $1 \%(\mathrm{w} / \mathrm{v})$ bovine serum albumin (BSA) for $30 \mathrm{~min}$. The specimens were probed with a primary antibody against $\alpha$-actinin (A-7811,

monoclonal anti- $\alpha$-actinin EA-53; Sigma-Aldrich, St. Louis, MO, USA) for $45 \mathrm{~min}$ Next, they were washed three times with PBS and immersed in PBS containing $1 \%$ BSA, an Alexa488-conjugated secondary antibody (Life Technologies, Carlsbad, CA, USA), and Alexa546-phalloidin (Life Technologies) for $45 \mathrm{~min}$. The specimens were washed three times with PBS and observed under a FV1000 confocal laser scanning microscope (Olympus, Tokyo, Japan). Microscopic images of five fields per sample were randomly captured.

Measurement of total protein and cell nuclei. Tissue constructs were washed with PBS, and cellular proteins were extracted from the tissue constructs by

homogenization and freeze thawing. The total protein concentration was determined by the bicinchoninic acid method. The total number of nuclei in the tissue construct was counted using NucleoCassette ${ }^{\mathrm{TM}}$ and NuceloCounter (Chemometec, Allerød, Denmark).

Western blot analysis. Protein samples $(20 \mu \mathrm{g})$ were mixed with SDS-PAGE sample buffer containing 2-mercaptoethanol and boiled at $100^{\circ} \mathrm{C}$ for $5 \mathrm{~min}$. The samples were then electrophoresed on a $6 \%$ (for MHC) or $12 \%$ (for myogenin, tropomyosin, and GAPDH) acrylamide gel and the proteins were then transferred to a polyvinylidene-fluoride membrane (GE Healthcare, Buckinghamshire, UK). After blocking with $5 \%$ skim milk in Tris-buffered saline containing $0.05 \%$ Tween 20 at $4{ }^{\circ} \mathrm{C}$ overnight, the membrane was incubated with anti-myogenin (F5D; Abcam, Cambridge, UK), anti-MHC (H300; Santa Cruz Biotechnology, Santa Cruz, CA, USA), anti-tropomyosin (TM-311; Abcam), or anti-GAPDH (14C10; Cell Signaling 
(a)

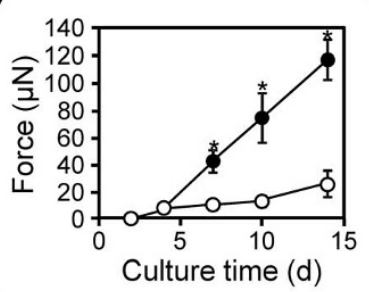

(c)

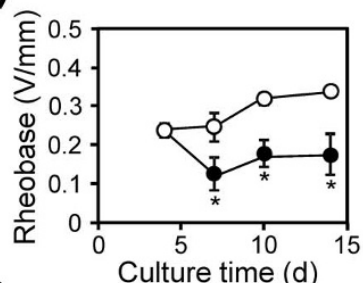

(e)

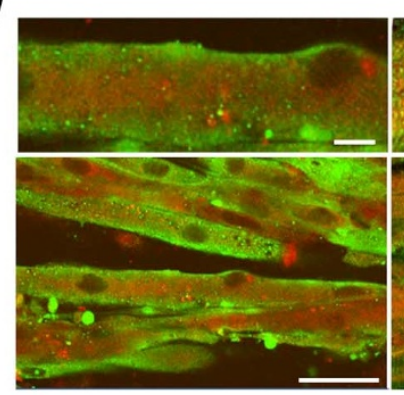

(f)
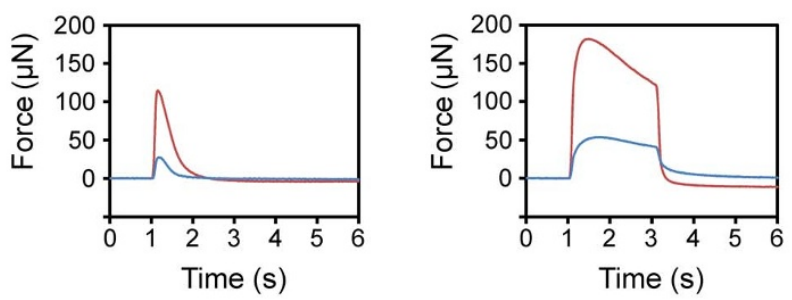

Figure $4 \mid$ The effects of EPS on in vitro skeletal muscle tissues at day 14 . The tissue constructs were cultured with continuous $1 \mathrm{~Hz}$ EPS at 0.3 $\mathrm{V} / \mathrm{mm}$ and $4 \mathrm{~ms}$ from days 4 to 14 . (a) The time course of force production by tissue constructs cultured with (closed circles) or without (open circles) continuous EPS. The data are expressed as mean \pm SD of three constructs. $* P<0.05$ vs. non-EPS constructs. (b) The time course of $\% \mathrm{Pt}$ in the tissue constructs cultured with continuous EPS from days 4 to 14 . The data are expressed as mean \pm SD of three constructs. (c) The time course of rheobase in the tissue constructs cultured with (closed circles) or without (open circles) continuous EPS from days 4 to 14. The data are expressed as mean \pm SD of three constructs. ${ }^{*} P<0.05$ vs. non-EPS constructs. (d) The expression profiles of muscle-specific proteins (myogenin, myosin heavy chain, and tropomyosin) in the tissue constructs by western blot during differentiation with $(+)$ or without $(-)$ continuous EPS from days 4 to 14 . (e) Immunostaining of the 14 day-culture tissue constructs for $\alpha$-actinin (green) and F-actin (red) cultured without (left) or with (right) continuous EPS. Upper photographs are magnified images. Scale bars, $50 \mu \mathrm{m}$ (magnified images, $10 \mu \mathrm{m}$ ) (f) Representative peaks of the twitch force (left) using a single electric pulse (voltage: $0.83 \mathrm{~V} / \mathrm{mm}$, width: $10 \mathrm{~ms}$ ) and fusion of tetanus (right) stimulated with multiple electric pulses (voltage: $0.83 \mathrm{~V} / \mathrm{mm}$, width: $10 \mathrm{~ms}$, frequency: $50 \mathrm{~Hz}$, duration: $2 \mathrm{~s}$ ). Tissue constructs were cultured without (blue lines) or with (red lines) continuous EPS.

Technology, Danvers, MA, USA) for $1 \mathrm{~h}$. The specific antibodies were detected using horseradish peroxidase-conjugated secondary antibodies (Santa Cruz Biotechnology) and a chemiluminescence detection kit (ECL detection system; GE Healthcare).
Video capture. The 14-day culture tissue constructs were stimulated with electric pulses of $0.83 \mathrm{~V} / \mathrm{mm}, 10 \mathrm{~ms}$, and $1 \mathrm{~Hz}$. Microscopic images of the contracting tissue constructs were recorded with a BZ-9000 microscope (Keyence). The videos were edited with time-lapse analysis software (Keyence).

Statistical analysis. The differences between two groups were analyzed using the Mann-Whitney rank sum test. The difference among multiple groups was analyzed using one-way ANOVA followed by post-hoc Tukey's multiple-comparison test. Data were considered statistically significant when $P<0.05$.

1. Levenberg, S. et al. Engineering vascularized skeletal muscle tissue. Nat. Biotechnol. 23, 879-884 (2005).

2. Liao, H. \& Zhou, G. Q. Development and progress of engineering of skeletal muscle tissue. Tissue Eng. Part B Rev. 15, 319-331 (2009).

3. Yin, H., Price, F. \& Rudnicki, M. A. Satellite cells and the muscle stem cell niche. Physiol. Rev. 93, 23-67 (2013)

4. Boonen, K. J., Rosaria-Chak, K. Y., Baaijens, F. P., van der Schaft, D. W. \& Post, $\mathrm{M}$. J. Essential environmental cues from the satellite cell niche: optimizing proliferation and differentiation. Am. J. Physiol. Cell Physiol. 296, C1338-1345 (2009).

5. Sekine, H. et al. In vitro fabrication of functional three-dimensional tissues with perfusable blood vessels. Nat. Commun. 4, 1399 (2013).

6. Okano, T. \& Matsuda, T. Tissue engineered skeletal muscle: preparation of highly dense, highly oriented hybrid muscular tissues. Cell Transplant. 7, 71-82 (1998).

7. Cheema, U., Yang, S. Y., Mudera, V., Goldspink, G. G. \& Brown, R. A. 3-D in vitro model of early skeletal muscle development. Cell Motil. Cytoskeleton 54, 226-236 (2003).

8. Ito, A. et al. Tissue engineering using magnetite nanoparticles and magnetic force: heterotypic layers of cocultured hepatocytes and endothelial cells. Tissue Eng. 10, 833-840 (2004).

9. Ito, A. et al. Construction and harvest of multilayered keratinocyte sheets using magnetite nanoparticles and magnetic force. Tissue Eng. 10, 873-880 (2004).

10. Akiyama, H., Ito, A., Kawabe, Y. \& Kamihira, M. Genetically engineered angiogenic cell sheets using magnetic force-based gene delivery and tissue fabrication techniques. Biomaterials 31, 1251-1259 (2010).

11. Yamamoto, Y. et al. Functional evaluation of artificial skeletal muscle tissue constructs fabricated by a magnetic force-based tissue engineering technique. Tissue Eng. Part A 17, 107-114 (2011).

12. Ross, J. J., Duxson, M. J. \& Harris, A. J. Neural determination of muscle fibre numbers in embryonic rat lumbrical muscles. Development 100, 395-409 (1987)

13. Chen, W. Electroconformational denaturation of membrane proteins. Ann. N. Y. Acad. Sci. 1066, 92-105 (2005).

14. Donnelly, K. et al. A novel bioreactor for stimulating skeletal muscle in vitro. Tissue Eng. Part C Methods 16, 711-718 (2010).

15. Fujita, H., Hirano, M., Shimizu, K. \& Nagamori, E. Rapid decrease in active tension generated by $\mathrm{C} 2 \mathrm{C} 12$ myotubes after termination of artificial exercise. J. Muscle Res. Cell Motil. 31, 279-288 (2010).

16. Dennis, R. G. \& Kosnik, P. E. 2nd. Excitability and isometric contractile properties of mammalian skeletal muscle constructs engineered in vitro. In Vitro Cell Dev. Biol. Anim. 36, 327-335 (2000).

17. Kosnik, P. E., Faulkner, J. A. \& Dennis, R. G. Functional development of engineered skeletal muscle from adult and neonatal rats. Tissue Eng. 7, 573-584 (2001).

18. Huang, Y. C., Dennis, R. G., Larkin, L. \& Baar, K. Rapid formation of functional muscle in vitro using fibrin gels. J. Appl. Physiol. 98, 706-713 (2005).

19. Hinds, S., Bian, W., Dennis, R. G. \& Bursac, N. The role of extracellular matrix composition in structure and function of bioengineered skeletal muscle. Biomaterials 32, 3575-3583 (2011).

20. Sun, Y., Duffy, R., Lee, A. \& Feinberg, A. W. Optimizing the structure and contractility of engineered skeletal muscle thin films. Acta Biomater. 9, 7885-7894 (2013).

21. Yaffe, D. \& Saxel, O. Serial passaging and differentiation of myogenic cells isolated from dystrophic mouse muscle. Nature 270, 725-727 (1977).

22. Fujita, H., Nedachi, T. \& Kanzaki, M. Accelerated de novo sarcomere assembly by electric pulse stimulation in C2C12 myotubes. Exp. Cell Res. 313, 1853-1865 (2007).

23. Tandon, N. et al. Electrical stimulation systems for cardiac tissue engineering. Nat. Protoc. 4, 155-173 (2009).

24. Wang, B. et al. Myocardial scaffold-based cardiac tissue engineering: application of coordinated mechanical and electrical stimulations. Langmuir 29, 11109-11117 (2013).

25. Radisic, M. et al. Functional assembly of engineered myocardium by electrical stimulation of cardiac myocytes cultured on scaffolds. Proc. Natl. Acad. Sci. U. S. A. 101, 18129-18134 (2004).

26. Cairns, S. P., Chin, E. R. \& Renaud, J. M. Stimulation pulse characteristics and electrode configuration determine site of excitation in isolated mammalian skeletal muscle: implications for fatigue. J. Appl. Physiol. 103, 359-368 (2007).

27. Khodabukus, A. \& Baar, K. Defined electrical stimulation emphasizing excitability for the development and testing of engineered skeletal muscle. Tissue Eng. Part C Methods 18, 349-357 (2012). 
28. Knuttgen, H. G. Strength training and aerobic exercise: comparison and contrast. J. Strength Cond. Res. 21, 973-978 (2007).

29. Chargé, S. B. \& Rudnicki, M. A. Cellular and molecular regulation of muscle regeneration. Physiol. Rev. 84, 209-238 (2004).

30. Naumann, K. \& Pette, D. Effects of chronic stimulation with different impulse patterns on the expression of myosin isoforms in rat myotube cultures. Differentiation 55, 203-211 (1994).

31. Shinkai, M. et al. Intracellular hyperthermia for cancer using magnetite cationic liposomes: in vitro study. Jpn. J. Cancer Res. 87, 1179-1183 (1996).

32. Yamamoto, Y. et al. Preparation of artificial skeletal muscle tissues by a magnetic force-based tissue engineering technique. J. Biosci. Bioeng. 108, 538-543 (2009).

33. Gawlitta, D., Boonen, K. J., Oomens, C. W., Baaijens, F. P. \& Bouten, C. V. The influence of serum-free culture conditions on skeletal muscle differentiation in a tissue-engineered model. Tissue Eng. Part A 14, 161-171 (2008).

\section{Acknowledgments}

This work was financially supported in part by Grants-in-Aid for Scientific Research (nos. 23686121, 22-2293, and 24-9911) from the Japan Society for the Promotion of Science (JSPS).

\section{Author contributions}

A.I., H.F., E.N., Y.K. and M.K. were involved in the design of experiments. Y.Y., M.S., K.I., M.Y. and E.N. conducted the experiments and analyzed the data. A.I., Y.Y. and M.K. wrote the manuscript. A.I. and Y.Y. contributed equally to the study. All authors discussed the results and commented on the paper.

\section{Additional information}

Supplementary information accompanies this paper at http://www.nature.com/ scientificreports

Competing financial interests: The authors declare no competing financial interests. How to cite this article: Ito, A. et al. Induction of functional tissue-engineered skeletal muscle constructs by defined electrical stimulation. Sci. Rep. 4, 4781; DOI:10.1038/ srep04781 (2014).

This work is licensed under a Creative Commons Attribution-NonCommercialNoDerivs 3.0 Unported License. The images in this article are included in the article's Creative Commons license, unless indicated otherwise in the image credit; if the image is not included under the Creative Commons license, users will need to obtain permission from the license holder in order to reproduce the image. To view a copy of this license, visit http://creativecommons.org/licenses/by-nc-nd/3.0/ 